\title{
AN INCOMPLETE FORM OF MANDIBULO-FACIAL DYSOSTOSIS (FRANCESCHETTI'S SYNDROME)*†
}

B Y

\author{
Gy. P. Halberg and J. M. Paunessa
}

ARGENTINA

IN 1944, Franceschetti and $Z$ wahlen (Geneva), after a careful study of the literature, gave a detailed description of two cases of a new symptom-complex affecting the bony structure of the face : mandibulo-facial dysostosis. On studying these cases, it became apparent that a new set of well-defined clinical and anatomical signs was common to all those afflicted with this dysostosis. It is due to Prof. Franceschetti who correlated the symptoms and signs of isolated cases, that the condition is now recognised as a well defined ophthalmological entity.

\section{Presént Case-History}

Julio J., a six-year-old boy, was brought to the out-patient clinic because of a convergent squint. The right eye was convergent (anti-mongoloid type) from birth. The use of spectacles did not reduce the angle of squint. The patient's ophthalmological history was otherwise negative.

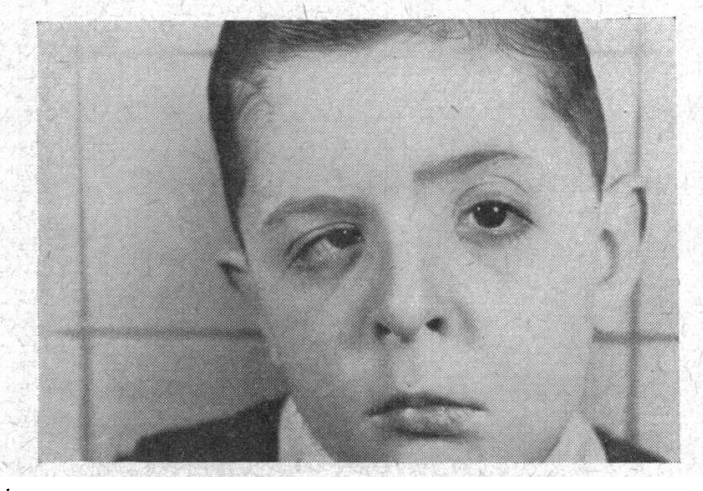

FIG. 1.

Front view of the patient.

Eye examination :-

Vision.-R. eye: 0,4 without and 0,6 with correction. L. eye : 0,8 without and 0,9 with correction.

Horizontal deviation: on tangent scale $+50^{\circ}$; on synoptiscope $+55^{\circ}$.

Vertical deviation: L. hyperphoria of $30^{\circ}$.

$\because$ * From the Instituto Oftalmologico Pedro Lagleyze, Buenos Aires, Argentina. Director : Professor Dr. Jorge L. Malbran.

+ Received for publication, March 1949. 
The patient had abnormal retinal correspondence. A pseudo-von Graefe sign was elicited on the left side.

In short, the eye examination revealed convergent strabismus, contracture of the inferior oblique muscle of the left eye, alternating hyperphoria, pseudo-von Graefe sign on the left, bilateral hypermetropic astigmatism, amblyopia of the right eye. We noticed an asymmetry of the face and a resemblance to previously

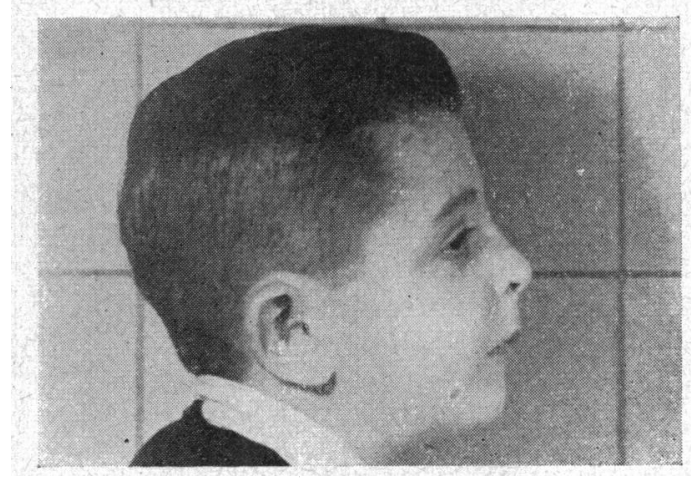

FuG. 2.

Right profile view of the patient

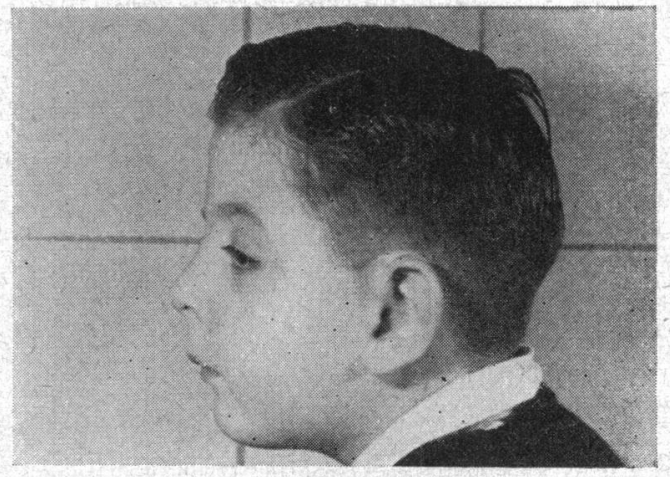

FIG. 3.

Left profile view of the patient.

observed cases of mandibulo-facial dysostosis. The right side of the face was particularly suggestive of this condition.

This patient was examined along the lines laid down by Franceschetti and Zwahlen (1944) (Figs. 1, 2 and 3):

1. Palpebral fissures, eyelids, eyelashes: There was an obliquity of the palpebral fissures of $20^{\circ}$ on the right and $15^{\circ}$ on the left. They measured $30 \mathrm{~mm}$. and $26 \mathrm{~mm}$. on the right and left side, respectively. They were triangular in shape by reason of a downward traction of the external part of the lower lid. 
This condition was more prominent on the right. The eyelashes consisted of a double row on the lower lids, and were very long on the upper lids.

2. Upper and lower jaws, palate and teeth: The patient had a superior prognathism and a slightly atrophic, receding chin. The palate had an ogival form (Fig. 4). The implantation of the teeth was very anomalous.

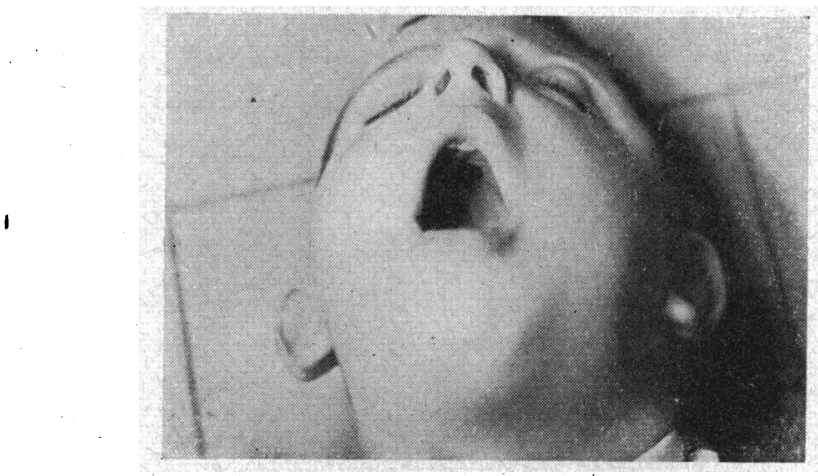

FIG. 4.

The palace of the patient.

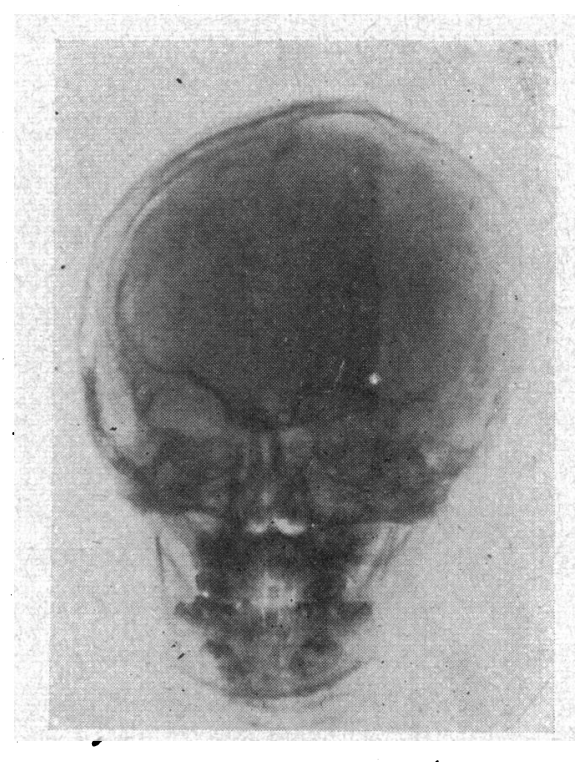

FIG. 5.

3. The malar bones were atrophic, especially on the right, leading to facial asymmetry.

4. The external, middle and internal ears showed no signs of malformation.

5. The naso-frontal angle was completely absent.

6. No macrostomia or fistulae on the cheeks were seen. 
$X$-ray findings (Figs 5, 6, 7 and 8)

$\mathrm{X}$-ray studies showed a marked facial asymmetry. The anterio-posterior diameter of the cranium was increased (dolichocephaly), and the digitate impressions were large and well-formed. The sella turcica was small and showed very clearly a hyperostosis of the sphenoid bone. The sphenoidal sinus was rudimentary and

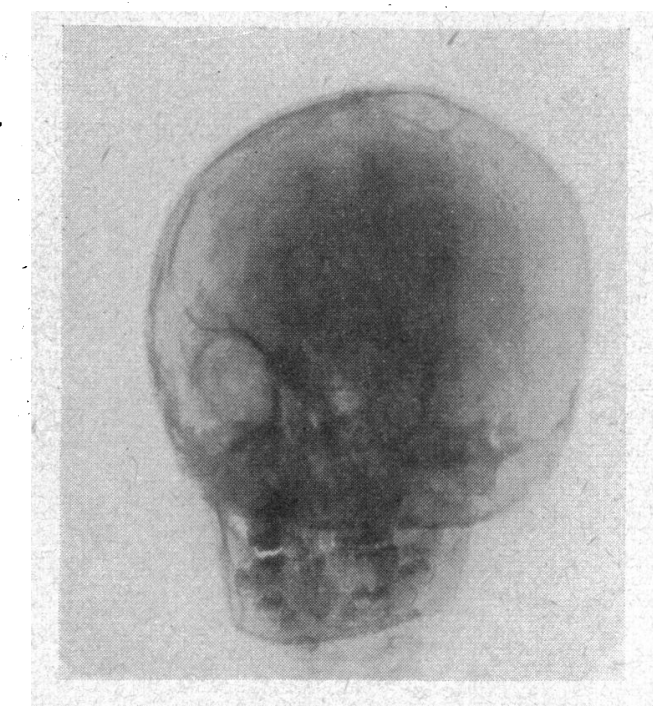

Fig. 6 .

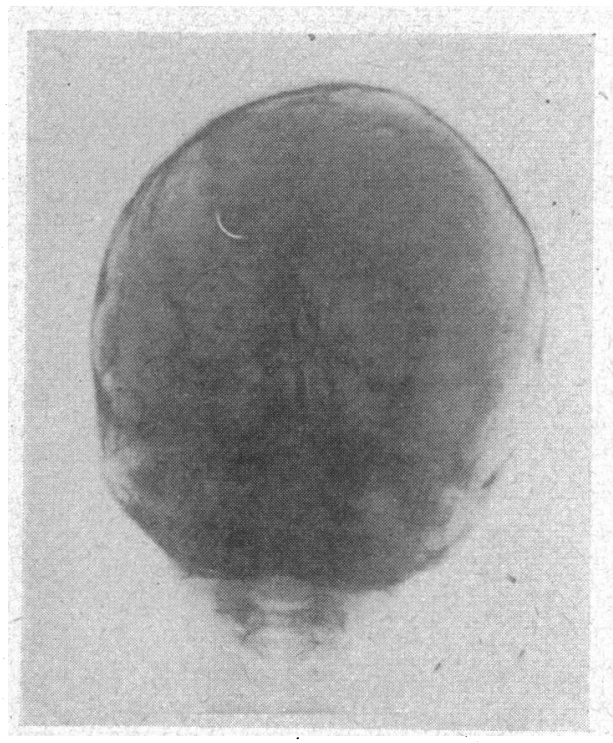

FiG 7. 
of the hypoplastic type. The frontal sinuses were small and hypoplastic. The mandible also showed hypoplasia. The nasal septum and the vomer.were deviated. The palate was in the form of a pointed arch. The orbital perimeter was unequal and orbital asymmetry was evident.

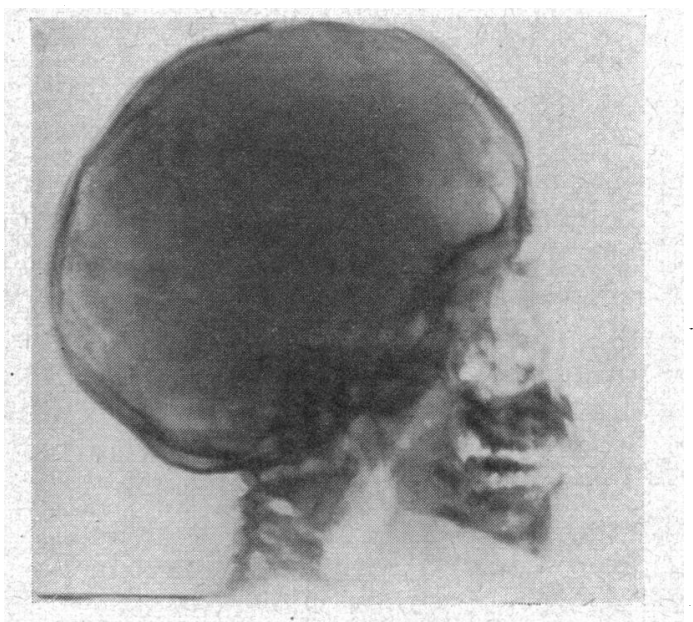

Fig. 8.

General physical and mental examinations

The physical and mental development of the patient were normal for his age. The physical constitution of the patient showed a distinct tendency to the adiposo-genital type.

\section{Summary}

The examination of a 6 year-old boy gave the authors the opportunity to describe a case of an incomplete form of mandibulofacial dysostosis (Franceschetti's syndrome).

It was characterised by :

1. Oblique palpebral fissures and dropping of the lower lids, as well as anomalous implantation of the lashes.

2. Superior prognathism and atrophy of the chin.

3 . Atrophy of the malar bones.

4. Ears normal.

- 5. Complete absence of the naso-frontal angle.

6. No macrostomia or fistulae on the cheeks.

\section{REFERENCES}

Franceschetti, A. (1944).-Bull. Schweiz. Akad. med. Wiss., 1, 60. Johnstone, L. (1943).-Brit. Jl. Ophthal:, 27. 21.

MANN, I. and KILNER, T P. (1943).-Brit. J. Ophthal., 27, 13.

VAN LiNT, A. and HeNNEBERT, P. (1936). - Bull. Soc. belge d'Ophtal., 73, 51.

WAAR DEN BU RG, P. J. (1934).-Klin. Monatsbl. f. Augenheilk., 92, 29.

(1948). - In SoRSBY, A., Modern trends in Ophthalmology. London. 2, 178.

ZWAHLEN, P. (1944). - Un syndrome noveau : la dysostose mandibulo-faciale (Thesis No. 1826). Geneva. 